\title{
AVALIAÇÃO DO ENSINO DE ENFERMAGEM DENTRO DE UMA PROPOSTA EMANCIPADORA
}

\author{
TEACHING ASSESSMENT OF NURSING INTO AN EMANCIPATING PROPOSAL \\ EVALUACIÓN DE LA ENSEÑANZA DE ENFERMERÍA DENTRO DE UNA PROPUESTA \\ LIBERTADORA
}

\author{
Maria Francelina dos Santos ${ }^{1}$ \\ Maria de Fátima Cavalcante Lima ${ }^{2}$ \\ Maria Grasiela Teixeira Barroso ${ }^{3}$
}

\begin{abstract}
RESUMO: Na intenção de oferecer novas tecnologias de ensino, o Curso de Mestrado em Enfermagem da Universidade Federal do Ceará vem integrando os cursos de graduação e pós-graduação. O estudo objetivou avaliar uma disciplina do Curso de Graduação em Enfermagem, numa visão crítica e transformadora. A metodologia utilizada envolve o paradigma de avaliação emancipadora de SAUL (1995), contemplando três momentos: descrição da realidade, crítica da realidade e construção coletiva. Os resultados mais significativos foram: que o conteúdo seja compativel com a carga horária, com renovação metodológica e descentralização da avaliação. Concluíu-se o estudo percebendo como ponto crítico do ensino-aprendizagem a deficiência metodológica adotada na disciplina. Tem-se a certeza de que esta investigação traz contribuições para a relação ensino-aprendizagem na qual professor e aluno sejam sujeitos do processo, eliminando, assim, a posição do aluno de mero objeto manipulado pelo sistema e copiadores da cópia.
\end{abstract}

UNITERMOS: Avaliação educacional - Avaliação emancipadora.

\begin{abstract}
Intending to offer new teachhing technologies the Nursing Master Course at the Federal University of Ceará have been integrating the graduation and postgraduation courses. The study aimed at evaluating a subject in Nursing Graduation Couse in a critical and transforming point of view. The used methodology involves SAUL's (1995) emancipating evaluation paradigm contemplating three moments: reality description, reality criticism and collective construction. The most significant results were: the contaiint be compatible with the schedule, with methodological renewal and evaluation decentralisation. The study has been concluded perceiving the methodological deficiency adopted by the subject as a critical point. It is certain that this investigation brings contribution for teaching-learning relationship where professor and students are process subjects, eliminating, so, the student position of a mere system manipulated object and copy copiers.
\end{abstract}

KEYWORDS: Education assessment - Emacipating assessment - Nursing.

${ }^{1}$ Mestranda em enfermagem/UFC. Enfra. Assistencial da Secretaria de Saúde do Estado do Ceará. Sanitarista

${ }^{2}$ Mestranda em enfermagem/UFC. Enfra. do Hosp. Universitário Walter Cantídio /

Especialista em enfermagem do trabalho.

${ }^{3}$ Professora Emérita da UFC.

R. Bras. Enferm. Brasília, v. 51, n. 1, p. 63-76, jan./mar., 1998 
RESUMEN: En la intención de ofrecer nuevas tecnologías de enseñanza, el Curso de Maestrado en Enfermería de la Universidad Federal de Ceará, viene integrando los cursos de graduación y post graduación. El estudio objetivó evaluar una disciplina del Curso de Graduación en Enfermería, en una visión crítica y transformadora. La metodología utilizada abarca el paradigma de evaluación libertadora de SAUL (1995), considerando tres momentos: descripción de la realidad, crítica de la realidad y construcción colectiva. Los resultados mas significativos fueron: que el contenido sea compatible con la carga horaria, con renovación metodológica y descentralización de la evaluación. Se concluye el estudio notándose como punto crítico de la enseñanza-aprendizaje la diferencia metodológica adoptada en la disciplina. Se tiene la certeza de que esta investigación trae contribuciones para la relación enseñanza-aprendizaje en la cual el profesor y el alumno sean sujetos del proceso, eliminando, así, la posición del alumno de simple objeto manipulado por el sistema y copiadores de la copia.

UNITÉRMINOS: Evaluación educacional - Evaluación libertadora - Enfermería.

\section{INTRODUÇÃO}

No sistema de ensino aprendizagem, as transformações são inevitáveis. Muitas vezes, este processo de mudança se torna dificil por estarmos habituados ou enquadrados em determinado modelo. A aprendizagem deve ser entendida como um continuum de nascer, crescer e renascer.

Com efeito, surge a necessidade de adequaçăo das estratégias de ensino ao conteúdo e acompanhamento da evolução técnico-científica. É crucial, ainda, que sejam corrigidas as falhas, melhorando o que for necessário para alcance dos objetivos. Nesse âmbito, atua o profissional que ensina como um facilitador da aprendizagem, em que os alunos saem do estado de meros repetidores de regras acadêmicas, tornando-se veículos de questionamentos e conseqüente transformaçăo do sistema educacional.

$\mathrm{Na}$ intenção de oferecer profissionais para o ensino, aptos à prestação de qualificados serviços à comunidade, é que o Curso de Mestrado em Enfermagem da Universidade Federal do Ceará (UFC) proporciona um programa voltado para atender a tal necessidade. A nós, em cumprimento do mesmo objetivo, foi designada a tarefa de avaliar uma disciplina do Curso de Graduaçăo em Enfermagem da referida Universidade.

O mencionado estudo é avaliativo do primeiro semestre do currículo recémimplantado e o segundo período semestral da grade curricular anterior, estando centrado na disciplina Histologia e Embriologia Humanas.

Avaliar năo é fácil. Trata-se de uma missăo que exige cuidado e diligência, para a qual raramente alguém está significativamente preparado. Com base nessa concepção, é que demandamos a literatura específica, buscando, nos estudiosos, referenciais que nos levassem a conduzir o tema com o devido 
acerto, tomando como modelo a abordagem emancipadora preconizada por $\mathrm{Saul}^{4}$. O método utilizado neste estudo difere das linhas tradicionais pela determinação e o comprometimento em transformar a realidade.

"Avaliação emancipatória caracteriza-se como um processo de descrição $e$ crítica de uma dada realidade visando provocar a crítica, de modo a libertar o sujeito de condicionamentos deterministas" 4 .

Assim, avaliar é examinar para conhecer a natureza e julgar as manifestações de caráter intelectual de uma situação verdadeira, real, para convertê-la ou não. A fonte principal é a independência, a libertação. A avaliaçăo (com seus passos complementares) é indispensável no sistema ensinoaprendizagem.

"Avaliação escolar é o termômetro que permite confirmar o estado em que se encontram os elementos envolvidos no contexto. Ela tem um papel altamente significativo na educação, tanto que nos arriscamos a dizer que a avaliação é a alma do processo educacional. ${ }^{3}$ "

A avaliaçăo tem como função medir o estado em que se encontram os três segmentos - professor, aluno e conteúdo programático. Cabe ressaltar o fato de que a avaliação deve permear qualquer processo de implantação. Com a mudança do currículo de enfermagem, e sua implantação em 1997, surgiu a necessidade de uma avaliação processual para verificar se as disciplinas estão satisfazendo as necessidades do aluno no aperfeiçoamento de sua aprendizagem.

Portanto, uma avaliação do ensino-aprendizagem exige que se esteja atento para a formação desses futuros profissionais, de sorte que todos os componentes desta estreita relação devem esmerar-se para formar enfermeiros capazes de desempenhar a profissão com zelo e competência. Portanto, objetivamos avaliar a disciplina Histologia e Embriologia Humanas, ministrada para o Curso de Enfermagem da Universidade Federal do Ceará, numa nova visão crítica e transformadora.

\section{METODOLOGIA}

Foram considerados no estudo todo o contexto estrutural, de espaço físico, bem como as condições de aprendizado oferecidas ao aluno, o processamento e desenvolvimento da disciplina.

Como metodologia, utilizamos o paradigma de Avaliaçăo Emancipatória nas três vertentes teórico-metodológicas: avaliação democrática, crítica institucional e criação coletiva, que "caracteriza-se por um processo de descrição, análise e crítica de uma dada realidade visando transformá-la" ${ }^{4}$. Usamos, portanto, três momentos de investigação: descrição da realidade, crítica da realidade e construção coletiva. ${ }^{4}$ 
$\mathrm{Na}$ disciplina, estăo matriculados 60 alunos, sendo que 53 freqüentaram regularmente as aulas. Foram distribuídos $\mathbf{5 2}$ questionários, dos quais foram devolvidos 38, número que passou a constituir a amostra, da qual fazem parte, também, seis professores, concordes em participar do ensaio.

O período da coleta de dados correspondeu aos meses de abril a junho de 1997, para atender às necessidades advindas do período escolar. Nessa fase, procuramos conversar informalmente com os professores para captar suas percepções em relação à aprendizagem do aluno de enfermagem, como também usamos dessa mesma técnica com o estudante em relaçăo à própria aprendizagem.

Por fim, aplicamos, a alunos e professores, questionários sobre: a mudança do currículo; participação do aluno na relação ensino-aprendizagem, quanto ao planejamento e conteúdo programático; significado da avaliação para o aluno.

A análise de dados foi realizada a partir de todos os questionários devolvidos. Agrupamos as respostas de forma a contemplar os assuntos preestabelecidos.

Dentre todas as respostas, selecionamos as mais representativas e as analisamos, levando em consideração respostas paritárias dos alunos e professores. Em outros momentos, estas respostas estăo contempladas apenas pelos alunos. Para análise dos resultados, empregamos, ainda, códigos para identificar as respostas dos alunos do primeiro e segundo semestres, e professores, codificando-os da seguinte maneira: $\mathrm{A} / 1^{\circ} \mathrm{sem}$ (aluno do $1^{\circ}$ semestre), $\mathrm{A} / 2^{\circ}$ sem (aluno do $2^{\circ}$ semestre), $\mathrm{P}$ (professor).

\section{COMENTÁRIO E RESULTADOS}

- Descrição da Realidade

- A disciplina Histologia e Embriologia Humanas ministrada no Curso de Enfermagem da UFC é constituída de 8 créditos, compreendendo 120 horas, ficando distribuídas em 29 teóricas e 91 horas práticas. É ministrada em um anfiteatro, amplo, com uma acústica prejudicada por falta de um microfone, onde são reunidos alunos dos cursos de enfermagem $\mathbf{e}$ farmácia, formando um total de 120 discentes recebendo aulas teóricas juntos, com programa e objetivos comuns. A didática utilizada em sala de aula por nove professores segue um modelo tradicional: o professor esquematiza o conteúdo no quadro-giz e faz uma exposição verbal da matéria a ser estudada. Sistematicamente, as aulas são intercaladas para apresentaçăo de slides com gravuras, de forma a demonstrar melhor o assunto em estudo, facilitando, assim, a compreensão dos conteúdos. No momento da projeção, a sala fica totalmente escura. Posteriormente, objetivando a fixação dos conceitos abordados, é também utilizado o epidiascópio, através do qual são mostrados imagens de órgãos humanos e material citológico referente ao estudo. 
Percebe-se que as aulas obedecem a uma seqüência lógica, tanto na prática como na teoria, e sempre que há a troca de professores entre uma aula e outra, é feito um resgate do assunto abordado na aula anterior pelo professor seguinte, a fim de que năo haja quebra de continuidade, portanto, sem qualquer prejuizo na aprendizagem. Os professores procuram ministrar suas aulas citando exemplos práticos. Alguns docentes motivam a participação, jogando perguntas, enquanto outros fazem uma recapitulaçăo, solicitando que $o$ alunado repita em coro $\circ$ que foi estudado. Acresce referir, porém, o fato de que alguns não incentivam esta participaçăo.

O programa é o mesmo, tanto para farmácia como para a enfermagem. No decorrer das aulas, são oferecidos exemplos voltados para a prática de enfermagem e farmácia, principalmente quando o assunto se relaciona mais a um dos ramos do conhecimento. A avaliação é feita através de duas provas, teórica e prática. Cada professor elabora questōes referentes ao conteúdo dado, sendo que a correçăo é concentrada nas mãos da coordenaçăo da disciplina.

No que se refere à organizaçáo da disciplina, observamos que existe um funcionário na sala de aula, responsável pelo manuseio do equipamento audiovisual, como também pelo controle da frequêencia dos alunos. Há ainda um técnico e um eletricista, ambos para resolver qualquer problema de manutenção nos microscópios e na rede elétrica, em caso de um eventual defeito no momento das aulas teóricas e práticas.

Conversamos, várias vezes, com alunos e alunas, tendo sido as opiniōes muitos semelhantes. Alguns relataram que a sala é muito grande, o que atrapalha um pouco o aproveitamento, pois dificulta a audição. Disseram que não conhecem bem os professores, não formam vínculos, como também não há maior entrosamento com os colegas. Outros falaram que "acham ótimo", falando que as aulas săo boas, que o fato de estarem num anfiteatro năo interfere no aprendizado: "As aulas são bem dadas."

A partir dos questionários distribuídos aos docentes e discentes, analisamos as respostas.

\section{Sobre a mudança do currículo}

A mudança do currículo leva à interrelação que considero de suma importância, pois uma cadeira vista em algum semestre não será esquecida, ao contrário, será uma auxilio aos outros posteriormente (A $\left.11^{\circ} \mathrm{sem}\right)$.

Achei uma boa, uma vez que este novo currículo foi uma rápida identificação do acadêmico com a enfermagem. É ruim entrar de cara em matérias tão importantes como Anatomia e Histologia ( $\left.\mathrm{A} / 1^{\circ} \mathrm{sem}\right)$.

Acredito que ocorrerá um aprimoramento do curso com esta mudança. $O$ mundo evolui a cada dia que passa, e o nosso curso necessita acompanhar este progresso $\left(\mathrm{A} / 2^{\circ} \mathrm{sem}\right)$. 
A minha turma ainda segue o currículo velho, mas acho que é benéfica. Aumentou o número de estágios $\theta$ isso é muito bom (A2 ${ }^{\circ} \mathrm{sem}$ ).

Podemos afirmar que, nas respostas do $1^{\circ}$ e $2^{\circ}$ semestres, os alunos expressam a satisfação e reconhecem a importância desta mudança para seu atual estado de acadêmicos, bem como para sua condição de futuro profissional. Ainda referem quanto à evoluçăo dos tempos, enfatizando a necessidade de acompanharmos o progresso, uma vez que, neste momento em que o mundo está voltado para a globalização, a enfermagem não pode se omitir, pois necessita crescer cada dia mais para năo ser apanhada de surpresa por esse tipo de inovação, proveniente de um sistema político/tecnológico exclusivo de uma minoria dominante.

\section{Sobre a participação do aluno no ensino-aprendizagem}

Observando, questionando e participando ( $\left.\mathrm{A} 1^{\circ} \mathrm{sem}\right)$.

Tendo mais contato com os monitores e professores (A1 ${ }^{\circ} \mathrm{sem}$ ).

$\mathrm{Na}$ ajuda mútua durante as aulas (principalmente nas aulas práticas (A1 $1^{\circ}$ sem).

Fazendo questionamentos e se mostrando disposto a aprender o conteúdo exposto (A2 ${ }^{\circ}$ sem).

Numa aula dinâmica com a participação dos alunos, tirando dúvidas com os professores (A2 ${ }^{\circ}$ sem).

Uma demonstração de um interesse maior que a busca de nota e a valorização e profissionalismo do próprio corpo discente (A2 $\left.{ }^{\circ} \mathrm{sem}\right)$.

Que ele, ao terminar de cursar a disciplina, saiba pelo menos reconhecer os tecidos básicos isoladamente ou reunidos formando os órgãos e que tenha sempre em mente os tópicos principais de Embriologia Geral, sabendo também conhecer algumas malformações congênitas $(\mathrm{P})$.

A disciplina tem seu conteúdo fragmentado entre diversos professores $\theta$ eu náo tenho acesso a nenhum mecanismo de avaliação empregado na disciplina, portanto, esse "feedback" fica concentrado nas mãos da coordenação $(\mathrm{P})$.

Uma demonstração de interesse maior que a de busca da nota e a valorizaçăo e profissionalismo do corpo discente $(\mathrm{P})$.

Nas respostas, houve uma demonstraçăo de que no ensino-aprendizagem deve haver um dinamismo em sala de aula, proporcionando meios de caminhar juntos - aluno $x$ professor - envolvendo-se em uma relação mútua para melhor apreensão do conteúdo ministrado. Em contrapartida, deve incentivar o aluno a argumentar, questionar, sair do marasmo. Enquanto isto, o professor espera de retorno do discente um apanhado de conhecimentos referentes à disciplina dada, como também que haja valorizaçăo e um maior interesse pelo seu crescimento profissional. 
Um docente, em suas respostas, relata que a avaliação é propriedade privada da coordenaçăo da disciplina; todavia, foge da interação que observamos no decorrer da nossa coleta de dados. No entanto, não é só um amontoado de informaçōes técnico-científicas de que necessita o aluno, pois ele requer uma preparação para o mundo atual, onde enfrentará um mercado de trabalho em concorrência com grande contingente de profissionais, numa relação que, muitas vezes năo é tão ética como deveria ser.

O professor deve ter um relacionamento pedagógico que conduza a uma bem maior interação discente e docente e a uma construção do conhecimento através do qual ambos participem na mesma escala de valores. Há de se ter na devida conta o fato de que, no ensino atual e qualificado, o aluno não pode ser usado como objeto de manipulação do pedagogo, mas tem de ser capaz de fazer apreciaçōes críticas e desenvolver a criatividade.

$\mathrm{Na}$ educação "é preciso que haja construção e participação. Assim, o contato entre professor $e$ aluno será pedagógico se for construtivo $e$ participativo. Não pode haver mero ensino e mera aprendizagem. $O$ aluno não pode reduzir-se a um simples objeto de treinamento. Precisa ser sujeito. Somente educação de qualidade é capaz de promover o sujeito histórico, crítico e criativo. ${ }^{1}$ "

\section{Sobre o planejamento e conteúdo programático}

Sim, acho que a equipe é de professores supercapacitados e o conteúdo bem é administrado (A $11^{\circ}$ sem).

Não tenho o que reclamar. Todos os professores são interessados e atenciosos ( $\left.\mathrm{A} / 1^{\circ} \mathrm{sem}\right)$.

Eu acho muita coisa para ser vista em um semestre. (A $\left./ 1^{\circ} \mathrm{sem}\right)$.

Sim, observo um desempenho dos professores que, muitas vezes, não é percebido nas outras disciplinas (A $\left.2^{\circ} \mathrm{sem}\right)$.

Sim, há cronograma, inclusive organizado seguindo os feriados do semestre (A $\left./ 2^{\circ} \mathrm{sem}\right)$.

Não tenho nenhum comentário a fazer a respeito do conteúdo programático, acho que está correto (A/2 $\left.{ }^{\circ} \mathrm{sem}\right)$.

O conteúdo é abrangente; haveria quiçá necessidade de maior empenho por parte de alguns docentes e da própria chefia do Departamento para melhorar o material didático; uma vez que nossos slides estão deteriorados $(\mathrm{P})$.

Em alguns temas importantes urge uma divisão do conteúdo em outras aulas para evitar o acúmulo de informação, algo limitado, pelo tempo escasso $\theta$ número de créditos da disciplina $(\mathrm{P})$. 
Somente colocar a disciplina dentro dos interesses da enfermagem $\theta$ isto depende de cada professor (P).

A maioria dos alunos nas suas respostas se refere freqüentemente quanto ao conteúdo, dizendo que é excelente, bem organizado e que os professores são capacitados. Apenas um entre os estudantes se reporta ao acúmulo de informações em apenas um semestre letivo. De acordo com este pensamento, estão os professores quando contestam o conteúdo abrangente e a falta de empenho, por parte da chefia, em oferecer recursos para inovar o material didático. Evidenciam, também, a necessidade de um conteúdo específico para a enfermagem. Espera-se que não fique à mercê de cada professor, e sim de responsabilidade da equipe, a conformação do docente ao conteúdo programático. De tudo isso, depreende-se a necessidade de renovação dos recursos e físicos didáticos na sala, de aula bem como da constante atualização intelectual do professor, em busca de acompanhar sempre o estudo da arte da disciplina que ministra. "A qualidade começa pela adequação da quantidade. ${ }^{1 \text { " }}$

Cabe aos produtores do conhecimento reunir esta quantidade com a qualidade a fim de transformá-las para fortalecer a produção do conhecimento.

\section{Sobre o método utilizado e os recursos audiovisuais}

A aula teórica deveria diminuir o número de slides para ver se dá menos sono.

Não sei como confirmar isso, é interessante mas ao mesmo tempo convidanos para uma soneca. ( $\left.\mathrm{A} / 1^{\circ} \mathrm{sem}\right)$

O auditório, devido ser muito grande, não há uma percepção auditiva satisfatória (A11ำsem).

Alguns slides são velhos, mas no geral facilita muito o entendimento (A/1ำsem).

É ótimo ter uma aula prática subseqüente a uma aula teórica pois complementa $O$ aprendizado (A/2ำsem).

Nas aulas práticas, os professores são bem dinâmicos e colaboram muito no aprendizado e o método utilizado com desenhos no quadro e a observação no microscópio garantem uma boa comunicação (A/2ำsem).

De modo geral, o material está em bom estado, cabendo ao aluno tirar melhor proveito das informações contidas nele (A) $\left.2^{\circ} \mathrm{sem}\right)$.

Teoricamente o método é excelente, mas insisto que há de existir maior empenho dos docentes para que funcione $(\mathrm{P})$.

Até certo ponto, a nossa maior dificuldade (tanto para o corpo docente como para o discente) é o grande volume de matéria a ser ministrada em um espaço de tempo $(\mathrm{P})$. 
O método utilizado e os recursos audiovisuais são adequados à necessidade do aluno. Existe uma integração importante com aulas seguintes (P.)

Percebe-se uma grande contradição entre as respostas dos alunos do primeiro e segundo semestres, apesar de que os dois grupos estudam na mesma sala, no mesmo horário, com material, programa e professores comuns. Esta ocorrência levou-nos a refletir na idéia de que os alunos desconhecem as inovações que vêm ocorrendo no ensino, onde o aluno é sujeito deste, fazendo seus questionamentos, as próprias interpretações e elaborações.

Já na visão do professor, o método é excelente, enfatizando, dentre as dificuldades, a necessidade de maior empenho por parte de alguns professores e o grande volume de matéria a ser ministrado em pouco espaço de tempo.

\section{Sobre o significado da avaliação para o aluno}

- Um método viável, porém "estressante"; algumas vezes me sinto ansiosa e insegura. A avaliação é a prova do que aprendemos ao longo das aulas, ao ser avaliado me sinto aliviado (A $11^{\circ}$ sem.)

- O método de avaliação como é feito tem suas falhas, já que não mede conhecimentos; dessa forma sinto-me apreensiva comigo mesma, já que eu me avalio muito mais além das provas. (A/1 $\left.{ }^{\circ} \mathrm{sem}\right)$.

- Significa um mistério, existe questões nas provas que não são comentadas pelos professores dentro do assunto da matéria, e muitas vezes não são tiradas as questões do livro adotado. Na prática espera uma rapidez do aluno ao avaliar a lâmina, não espera que pense ou tente lembrar o nome de algo que esquecem na hora $\left(\mathrm{A} / 2^{\circ} \mathrm{sem}\right)$.

- A dificuldade é na prática que deveria ser mais prolongado o tempo para responder e eu não consigo entender porque na técnica a cada quatro questões erradas anula uma certa. Não vejo nenhum objetivo neste método ( $\left.\mathrm{A} / 2^{\circ} \mathrm{sem}\right)$.

A avaliação é absolutamente necessária, mas, da forma como é feita, leva os alunos ao estresse. Deveria ser repensada uma forma mais amena, com a qual o aluno não se sinta coagido, ao ponto de passar mal em sala de aula, como tivemos a oportunidade de observar durante uma avaliação prática. Esse tempo que os alunos reclamam é porque, nessa avaliação, 10 minutos são dados para que $\circ$ aluno visualize 10 lâminas,. sendo rigorosamente cronometrado 1 minuto para cada lâmina. "A avaliação, quer seja feita através de testes ou provas ou por ambos, deve realizar-se numa atmosfera que permita o crescimento do aluno, e não a criação de bloqueios ${ }^{3}$."

\section{- Crítica da realidade}

Mudar atitudes e comportamentos de pessoas que se acomodaram tem sua procedência na validação da compreensão da realidade. Desta feita, surge a 
necessidade de um posicionamento crítico e reflexão das idéias ultrapassadas que bloqueiam ensino-aprendizagem, pois o sistema de ensino deve estar em constante renovação, tanto nos conteúdos como no que se relaciona com métodos e técnicas.

Criticar esta disciplina é mister difícil, pois, nos aspectos gerais, apresenta-se boa. Mesmo que o nível de satisfação dos alunos seja bom, há de se convir que este resultado se relaciona com a comunicação do professor e domínio do tema a ser por ele apresentado. Contudo, alguns relataram deficiências por eles observadas, a nós competindo apenas pôr em evidência o fato de que slides e lâminas necessitam ser renovados, uma vez que alguns se encontram desbotados e sem uma boa visibilidade. O número excessivo de slides, apesar de $\circ$ assunto requerer, torna-se cansativo, pois a sala permanece totalmente escura por muito tempo, gerando monotonia e cansaço, sendo freqüente $\circ$ fato de estudantes adormecerem durante as projeções. Sentimos a necessidade destes slides, porém faz-se necessária uma melhor distribuição desses recursos durante as aulas. Quanto às lâminas, referiram, ainda, serem antigas e descoradas, o que impede a visualização no microscópio, dificultando determinar a estrutura estudada.

Percebemos, também, pelas respostas dos alunos e em nossas observações, a necessidade de mudança do comportamento e da didática de alguns docentes ainda acomodados.

O conteúdo, conforme questionam os professores e alunos, é abrangente, necessitando de uma reformulação e adequação à realidade da enfermagem. Portanto, cabe à equipe empenhar-se nessa reformulação, já que é questionado pelos dois segmentos o acumulo de informações, pois, muitas vezes, este conteúdo não é necessário para a formação do aluno. Urge também que se estabeleça maior envolvimento e empenho, por parte da chefia, em adquirir recursos para substituir os slides que estão velhos, conforme relataram doscente e discente em suas respostas, e consonante nossas observações. O método de exposição verbal anacrônico e cansativo de um dos professores induz a um esvaziamento da sala de aula, deixando aproximadamente $40 \%$ dos alunos em sala.

Também, a sala é muito ampla, dificultando a acústica, pois quem fica sentado atrás e nas laterais não consegue ouvir o que está sendo dito pelo professor em suas exposições. $\mathrm{O}$ ambiente é organizado à maneira tradicional; as cadeiras dispostas em filas, uma atrás da outra, com um formalismo inevitável, a começar pela disposição delas proporcionando esse ambiente formal, levando os alunos ao distanciamento.

O número de monitores é insuficiente para atender ao quantitativo de aluno durante a aula prática. É necessária, sempre, a presença do monitor, que presta 
maior assistência e os esclarecimentos necessários aos estudantes, principalmente quando da identificação de microorganismos através do aparelho.

É preciso rever o processo atual de avaliação clássica, que vem se arrastando por muitos anos no ensino, realizada de forma superficial, não medindo o conhecimento e o desempenho do aluno. Além do mais, os resultados das avaliações ficam concentrados nas mãos da coordenação da disciplina, impedindo que os demais professores participem de alguma forma deste processo. Ademais, não há um retorno para que possam avaliar o desempenho do aluno e do professor. O conteúdo programático é bem organizado, necessitando apenas ser mais específico para a enfermagem, enquanto a sistematização das aulas foi revelada como sendo bem coordenada.

Verificamos no campo de pesquisa e observamos nas respostas dos alunos e professores que o método de ensino utilizado para a disciplina de Histologia e Embriologia Humanas continua sendo repasse de conhecimentos, através do qual o aluno continua como objeto receptivo do ensino e o professor como sujeito copiado. "A aula copiada não constrói nada de distintivo, e por isso não educa mais do que a fofoca, a conversa fiada dos vizinhos, o bate-papo numa festa animada ${ }^{2} . "$

Este ensino deveria estar voltado para a formação da competência humana, conduzindo ao desafio da pesquisa e elaboração própria, utilizando questionamento levando assim à recriação da motivação qualitativa do ensinoaprendizagem, de forma a incentivar o aluno a construir a própria interpretação e elaboração.

\section{- Construção coletiva}

Esta fase do estudo compreende o terceiro momento da avaliação emancipadora preconizada por Saul ${ }^{4}$. Com ela pretendemos dar inicio ao esboço das percepçöes dos elementos envolvidos, quais sejam, alunos, professores e pesquisadores. Esse momento constituiu-se de uma criação coletiva, quando se faz reflexões com todos os segmentos que participaram da investigação. Essa construção coletiva permeou a investigação como um todo, a partir da deteç̧ão de problemas e dos contatos com professores e alunos. Inicialmente, fizemos reflexões sobre os dois primeiros momentos: descrição da realidade e crítica da realidade.

Em uma oficina com professores, a Coordenação de enfermagem e alunos, apresentamos os resultados das duas primeiras fases do estudo e participamos das críticas que consideramos construtivas. Todavia, como a construção coletiva é uma fase que demanda um ir-e-vir para facilitar as mudanças necessárias, restou-nos voltar aos professores e alunos para apreciação dos resultados conclusivos, o que determina a necessidade de uma segunda etapa dessa investigação, em outro momento distinto. 
Considerando o prejuizo que sofre o contingente estudantil, em decorrência do desconhecimento ou da não aplicabilidade dos novos métodos de ensinoaprendizagem que vem revolucionando o processo educacional, constata-se que falta consciência crítica do corpo discente e docente em relaçăo aos métodos aplicados em sala de aula.

Tendo-se em conta os resultados encontrados a partir desses primeiros momentos da disciplina estudada, percebemos, através da descrição da realidade e da sua análise e ainda pelas observações das pesquisadoras, que o ensino acadêmico continua muito aquém para acompanhar os avanços técnicocientíficos que se vêm propagando no mundo científico educacional nos últimos anos.

Evidenciamos, no decorrer do estudo, que se faz necessária uma reformulação didático-pedagógica configurada nos seguintes tópicos:

1. Situar a disciplina dentro dos interesses da enfermagem e rever o excesso de conteúdo programático, colocando-os dentro da realidade.

2. A equipe de professores, juntamente com a coordenação, deve pleitear recursos junto à Universidade, a fim de melhorar o material didático, como slides e lâminas.

3. Intercalar a apresentação e reduzir o número de slides expostos no decorrer das aulas, tornando-as mais dinâmicas, evitando que os alunos durmam durante as aulas.

4. Quando houver exposição de slides, apagar apenas as lâmpadas que ficam localizadas na frente, facilitando a comunicação, dinamizando mais a aula, evitando a dispersão dos alunos e, conseqüentemente, evadir-se de sala de aula.

5. Viabilização do processo de interação aluno/professor, através da utilização de uma didática moderna e adequada, tornando o clima afetivo fundamental para o processo ensino-aprendizagem.

6. Descentralização da avaliação das mãos da coordenação, isto é, que as provas sejam corrigidas pela equipe de professores e estes tenham retorno dessas avaliações.

7. Reavaliar o processo de avaliação de ensino aprendizagem, uma vez que este deverá ser construído a partir do primeiro contato com o aluno.

8. O professor deve observar o desempenho e participação em sala de aula, e distribuir melhor o horário de avaliação prática para que o aluno não se sinta coagido e estressado.

9. Utilizar-se de microfone para facilitar a comunicação em sala de aulas, visto que as aulas, como foi referido no corpo deste estudo, são ministradas em um anfiteatro. 
10. Rever o quantitativo de alunos em sala de aula por ocasião da matricula; quando houver excesso de alunos dividir as turmas.

11. Reivindicar, junto à universidade, o aumento de bolsas nessa disciplina, a fim de facilitar o aprendizado nas aulas práticas, cabendo aos Departamentos de Enfermagem e Morfologia incentivar junto os alunos para $\circ$ ingresso nessa monitoria, quer seja através de concurso ou voluntariamente.

Portanto, esperamos que o resultado deste estudo sirva para construçăo de melhores estratégias de ensino, no qual professor e aluno sejam sujeitos do ensino aprendizagem, aprendendo a fazer e refazer, construindo as próprias interpretaçб̄es e elaboraçб̃es, eliminando, assim, a posiçăo do aluno como mero objeto manipulado pelo sistema, na qualidade de copiadores da cópia.

\section{CONCLUSŐES}

Concluindo o estudo, na certeza de que a última fase demanda tempo e necessita de um decurso de discussão e construção coletiva, convictos estamos de que esta investigação traz contribuiçőes para o ensino-aprendizagem no que diz respeito às reflexőes dos segmentos envolvidos.

Em relaçáo aos alunos - Estes acreditam que as aulas devem ser dinâmicas, com participação dos alunos, valorização e profissionalismo do corpo discente. Relatam, também, um conteúdo bem administrado, porém, com excesso de informaçōes e slides. Cabe, então, a redução do uso excessivo de slides, adoção de medidas para melhorar a acústica, diminuir a dimensão da sala de aula. As aulas práticas são dinâmicas, mas o método de avaliação é estressante e com falhas, uma vez que existem questões nas provas que não foram discutidas em sala de aula; e a rapidez como é conduzida a avaliação prática também é feita de complicação para o aprendizado.

Em relaçăo ao professor - Estes esperam que no final da disciplina os estudantes devem dominar o conteúdo administrado. Os alunos devem ter consciência da abrangência do conteúdo e da necessidade de renovar o material didático; e ainda que a equipe deve se empenhar em colocar a disciplina dentro dos interesses da enfermagem, devendo haver também determinação da equipe para que o método de ensino funcione bem.

Estes itens também foram pontuados pelas pesquisadoras e acreditam que estes problemas detectados possam ser resolvidos em encontros posteriores produzindo discussão e construção coletiva. 


\section{REFERÊNCIAS BIBLIOGRÁFICAS}

1. DEMO, Pedro. Educação e qualidade. Campinas; Papirus, 1994.160 p..

2. Educação pela pesquisa. 2 ed. Campinas: Autores Associados,1997.120p..

3. SANT'ANNA, Ilza Martins. Porque avaliar? Como avaliar. crítica e instrumentos. Petrópolis: Vozes, 1995. 137 p.

4. SAUL, Ana Maria. Avaliaçäo Emancipatória: desafio à teoria e à prática de avaliação e reformulação de currículo. São Paulo: Cortez, 1995. 